\title{
Impact of the COVID-19 pandemic on psychological health status during lockdown period: A cross-sectional study
}

\author{
Sonu Punia', Mohini', Shailja Sharma르, Varun Singh ${ }^{1}$, Shabnam Joshi ${ }^{1}$ \\ ${ }^{1}$ Department of Physiotherapy, Guru Jambheshwar University of Science and Technology, \\ Hisar, Haryana, India \\ ${ }^{2}$ Psychology, BLJS College, Tosham, Haryana, India
}

\begin{abstract}
Objective. The aim of this research was access the effect of lockdown on the psychological health status of people. Methods. This was an online questionnaire survey developed and circulated among people using snow-ball sampling techniques from April to mid of June 2020. The online survey collected information on demographic data and psychosocial health elements.

Results. This study included 604 peoples ( $59.1 \%$ were female and $40.8 \%$ were females) of Haryana. Of the total respondents, $57.6 \%$ were in age group of $18-30$ years, $40.8 \%$ were in $31-45$ years and $1.5 \%$ was in $45-60$ years group. $90 \%$ of people have normal self- reported BMI, $6.5 \%$ were overweight, $3 \%$ were underweight and $0.5 \%$ people have obesity. $74 \%$ respondents were graduate, $11.5 \%$ postgraduate, $3.2 \%$ were $\mathrm{PhD}$, and $9.2 \%$ were 12 th pass. $31.8 \%$ were unemployed, $35.9 \%$ were student, $15.8 \%$ regular government employee, $4.7 \%$ were self- employed and $2.5 \%$ were adhoc/contract employee. $79.5 \%$ people reside in urban community and $16 \%$ in rural community and $4.5 \%$ in semi-urban area. Most of the respondents have agree with the statement that lockdown induced constant sense of insecurity (72.9\%); anxiety (58.7\%),psychological stress $(66.4 \%)$; work \& financial stress $(52.4 \%)$, phobia of infection (50.9\%); stigma towards symptomatic people, which might be because of simple flu $(55.2 \%)$; stress from watching \& listening COVID-19 news (38.6\%); stress from practice of prevention measure (31.9\%). Most of people also agree with that behavior-change modification (follow preventive regulations) can improve mental stress $(53.2 \%)$.

Conclusion. Majority of people has realized the lockdown have significant impact on psychological health status of people.
\end{abstract}

Keywords: COVID-19, psychological health, stress

\section{INTRODUCTION}

COVID-19 [corona virus disease 2019] epidemic was began at Wuhan, China in December 2019 and rapidly propagate to other countries by migration of the people [1]. By $30^{\text {th }}$ January, 2020, people in India started get infected by the COVID-19 virus which is highly contagious and thus the cases were start increasing exponentially. To address this situation and to reduce the spreading of the virus, Indian government decided to completely lockdown the entire country [2].

COVID-19 is impacting a large number of populations both physically and psychologically.
Since February 2020, epidemic prevention come in concern and since then the real initiation of global concern takes place, indicating enormous impacts in almost every aspect. This out-breaking nevertheless increasing the burden on hospitals, doctors and global economy, meanwhile the impact of this infection on global psychological health is being neglected [3].

] The low predictability, uncertainty and long incubation period leads to exhaustion, fear and anxiety in the healthy population [4]. The preventive measures like lockdown, social distancing, self-isolation, proper sanitization tends to develop 
abnormal psychological behavior like avoidant behavior, anxiety, obsessive-compulsive behavior etc. in general population [5]. Due to exponential growth of number of patients, there is increase in the strictness in the lockdown and closure of social gatherings like school, colleges and Universities is affecting the students' mental health and leads to worries and anxiety in concern with future [6]. Less interaction with the family members, self-isolation and lack of social interactions are the main risk factors of the negative effect on mental health and resulting in loneliness, anxiety, depression and constant feeling of fear. This negative effect, although protect the individual from the pathogen itself in terms of disease but in long term consequences, it may reduce individual's normal healthy psychological mechanisms and when chronic it can result in some severe psychiatric disorders [7].

Healthy individual's feels stigma towards people with symptoms such as cold, cough or sneezing while it might just be a simple flu or cold which meanwhile creates mental pressure.

Media and news channels also create constant mental pressure by showing exaggerated reports which might not be that serious issue. Social media spreads misinformation and false claims about factors related to causation, mortality and morbidity rates, prevalence etc which leads to insecurities, anxiety and worries in individuals [8]. These uncertainties about the future, outcomes in long term and lack of proper and valid information have negative consequences in population's mental health and daily life [9].

As the key strategies for the prevention of disease are isolation and social distancing, these both are affecting the psychological status of the healthy population. Following are some ways in which COVID-19 can affect the population- constant feeling of fear, frustration, insecurity and anxiety, fear of losing their jobs due to lockdown, avoidant behavior towards people having flu like symptoms, obsessive-compulsive behavior to follow the preventive measures like hand hygiene, sanitization or need to hoard food, medical or essential supplies, depression due to worries about future and lack of interaction which family members. These psychological stressors can lead to long- term mental health problems and should be address timely [10].

The most frequent affected groups from psychological distress could be older people due to their high prevalence, patients with previous psychological disorder, the family of the infected person and the health workers [10].

Most probably in the upcoming time, world will face increase in psychological health issues, behavioral disorders, as burden on the health sector and after this pandemic is over, it's after- effects on the population's mental health will be seen for a long time. Hence time is demanding to increase concern in the field of psychological health of the population. Investigators and researchers should study and analyze the impact of pandemic during lockdown on the mental health of the population to consider it timely so that a theoretical basis for psychological intervention to be used to minimize its effects could be explored [11].

Early identification, early supportive therapy and monitoring, management of respiratory failure and prevention of complications are the mainstay of the treatment and there is no definitive treatment is available but studies are being done on the effectiveness of the Plasma Therapy. Due to lack of definitive treatment and long incubation period, general population is facing a constant feeling of fear and as the India is densely populated country without sufficient health professionals, it is difficult for the general population to cope up with the psychological distress because even the developed countries like America are not able to get hold on this highly infectious disease. Hence it is necessary to psychological domains of the population in India [12].

Investigators and researchers should study and analyze the impact of pandemic during lockdown on the mental health of the population to consider it timely so that a theoretical basis for psychological intervention to be used to minimize its effects could be explored. To understand and study the impact on psychological and psychiatric consequences of the pandemic, such as anxiety, exhaustion, frustration, depression, fears etc. Researchers should come forward. Previous research had done to explore the effect of COVID-19 in different countries. Hence, this study aimed at exploring the impact of COVID-19 pandemic on psychological health during lockdown period of the normal healthy population.

\section{METHODOLOGY}

A sample of 604 individuals was participated in this study through online survey which was creat- 
ed by Google docs form and circulated through emails and social media by snow-ball sampling method. This is a cross-sectional survey of population comprised individuals facing lockdown in India. 604 respondents from different states like Haryana, Delhi, Himachal Pradesh, and Rajasthan.

The inclusion criteria of study are participants should be from India, age group (18 years to 60 years), people of any occupation and any ethnic group. The participation of population was excluded if they have any previous mental impairment or any vocal or communication impairment.

TABLE 1. Self-made questionnaire

\begin{tabular}{|c|c|}
\hline Q. No. & Questions \\
\hline 1. & $\begin{array}{l}\text { Feeling of insecurity for oneself and family during } \\
\text { COVID-19 pandemic. }\end{array}$ \\
\hline 2. & $\begin{array}{l}\text { Anxiety due to lack of social interactions because of } \\
\text { home-isolation during this pandemic. }\end{array}$ \\
\hline 3. & $\begin{array}{l}\text { The phobia of going out of home during lockdown } \\
\text { period. }\end{array}$ \\
\hline 4. & $\begin{array}{l}\text { Feeling stigmatized towards people present with } \\
\text { symptoms which might be because of simple flu } \\
\text { which in-turn creates mental pressure. }\end{array}$ \\
\hline 5. & $\begin{array}{l}\text { Anxiety due to fear of getting infected or reliving a } \\
\text { pandemic with a history of any infectious disease like } \\
\text { lungs disease, heart disease, kidney disease and any } \\
\text { other infection like Nipah, Ebola or SARS). }\end{array}$ \\
\hline 6. & $\begin{array}{l}\text { Mental stress because of growing panic which is } \\
\text { due social media's rumors and false claims during } \\
\text { cOVID-19 pandemic }\end{array}$ \\
\hline 7. & $\begin{array}{l}\text { Anxiety, frustration, fatigue and fear of contraction of } \\
\text { infection in frontline persons like healthcare workers } \\
\text { or media/news persons. }\end{array}$ \\
\hline 8. & $\begin{array}{l}\text { Stress from work, financial stress, stress from home } \\
\text { creates horrified feelings, apprehension and helpless } \\
\text { felling during COVID-19 pandemic }\end{array}$ \\
\hline 9. & $\begin{array}{l}\text { Feeling of anxiety while watching or reading news } \\
\text { about COVID-19 }\end{array}$ \\
\hline 10. & $\begin{array}{l}\text { Does coping strategies like alcohol or drug abuse } \\
\text { helps in reducing stress during pandemic. }\end{array}$ \\
\hline 11. & $\begin{array}{l}\text { Stress and the feelings under pressure associated } \\
\text { with work from home during lockdown period }\end{array}$ \\
\hline 12. & $\begin{array}{l}\text { Practice prevention measures (e.g. Handwashing, } \\
\text { social distancing etc.) creates mental stress }\end{array}$ \\
\hline 13. & $\begin{array}{l}\text { Lockdown period can lead to loneliness and } \\
\text { depression like feelings }\end{array}$ \\
\hline 14. & $\begin{array}{l}\text { Is there any lifestyle change in before and during } \\
\text { outbreak in concern of spending more or less time to } \\
\text { exercise rest or relax? }\end{array}$ \\
\hline 15. & $\begin{array}{l}\text { Behavior-change modification (follow preventive } \\
\text { regulations) can improve your mental stress }\end{array}$ \\
\hline
\end{tabular}

A self-reported questionnaire was made and shared through emails and social media to the convenient samples. In addition, every respondent was encouraged to share the questionnaire to the new respondents from his/her contacts. We assessed the psychological health of the population during lockdown period by the questionnaire that contains different questions which inquired the following-demographic details, knowledge and concern about COVID-19 and lockdown and mental health status during lockdown period which may consists of emotional indicators like depression, anxiety, fear, frustration, etc. The questionnaire contained 15 questions and those were all compulsory. The response was followed the criteria of strongly agree, agree, neutral, disagree and strongly disagree. The details of questions described in following table 1 .

\section{DATA ANALYSIS}

Data responses were presented in the form of percentage and pie chart (figures 1-15).

\section{RESULTS}

This study included 604 respondents $(59.3 \%$ were females and $40.6 \%$ were males) living in Haryana, Rajasthan, Himachal Pradesh and Delhi.

Of the 604 respondents, 57.3\% participants were between the age group 18 to $30,40.9 \%$ participants were between 31 years to 45 years age group, and the remaining $1.8 \%$ was above the age of 45 years. Out of the total respondents $90.1 \%$ participants were reported under normal BMI, the $4.9 \%$ participants were overweight, $3.8 \%$ participants had report their BMI as underweight and the remaining $1.2 \%$ participants were having obesity.

$35.8 \%$ participants samples were students, $31.6 \%$ participants were unemployed, $9.6 \%$ participants were working in private sector, $15.7 \%$ participants were government employers and the remaining $7.3 \%$ participants were either self-employed or working under contract basis.

Out of 604 respondents $74.2 \%$ participants were graduate students, $11.4 \%$ participants were postgraduate, $9.1 \%$ participants were studying in school, and the remaining 5.3\% participants were either $\mathrm{PhD}$ scholars or any other.

Out of 604 respondents, $72.8 \%$ agreed that they had feeling of insecurities for oneself and family, they also report that they feel anxiety due to lack of social contacts and meetings. 13.2\% respondents were strongly agreed that they were living with the phobia of going out during lockdown period. $70.3 \%$ respondents were under mental pressure 
Q1. A constant sense of insecurity for oneself and loved ones during COVID-19 pandemic:Untitled Question 604 responses

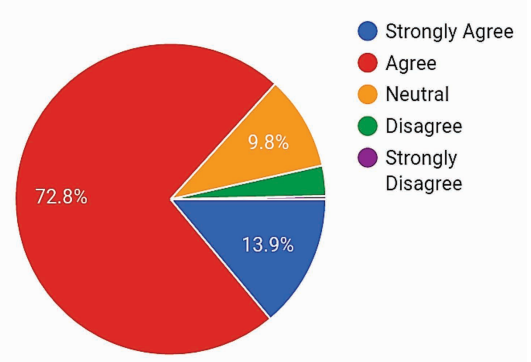

Q 4. Stigma towards people with symptoms such as cold, cough or sneezing, which might just be a simple flu creates mental pressure.

604 responses

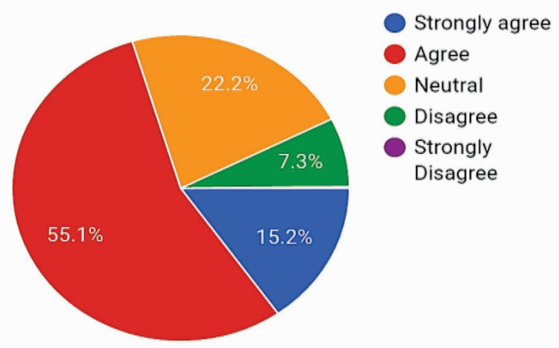

Q 2. Anxiety of social/physical distancing resulting in lack of contact with family or friends who may be living far away during COVID-19 pandemic.

604 responses

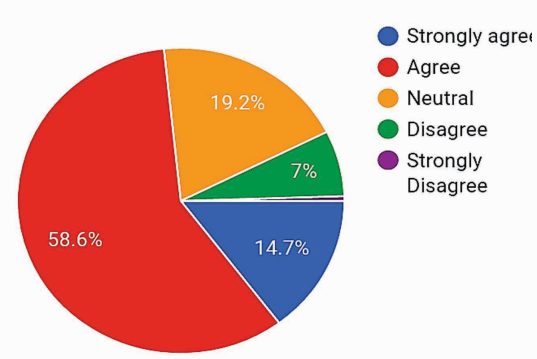

Q5. The fear of reliving a pandemic if you have lived through another infectious disease pandemic/epidemic in your lifetime (such as lungs disease, heart disease, kideney disease and any other infection like Nipah, Ebola or SARS).

604 responses

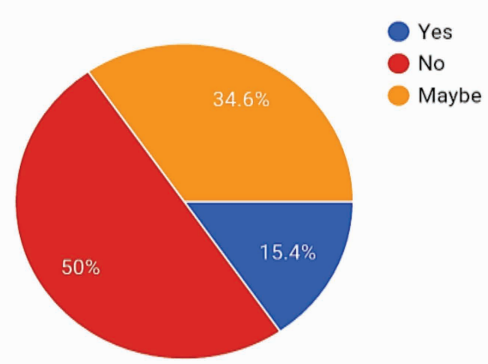

Q 8. Stress from work, financial stress, stress from home creates horrified feelings, apprehension and helpless felling during COVID-19 pandemic

604 responses

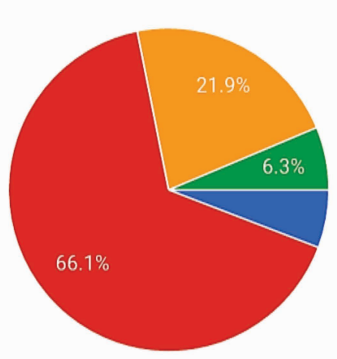

Strongly agree

- Agree

Neutral

Disagree

Strongly

Disagree
Q 9. Watching, reading or listening to news about COVID-19 that causes you to feel anxious or distressed 604 responses

Q 7. In healthcare workers, paramedics, volunteers, virologists or media persons at the frontline of the COVID-19 control or coverage: fatigue, burnout, frustration or the fear of contracting or guilt of transmitting infection.
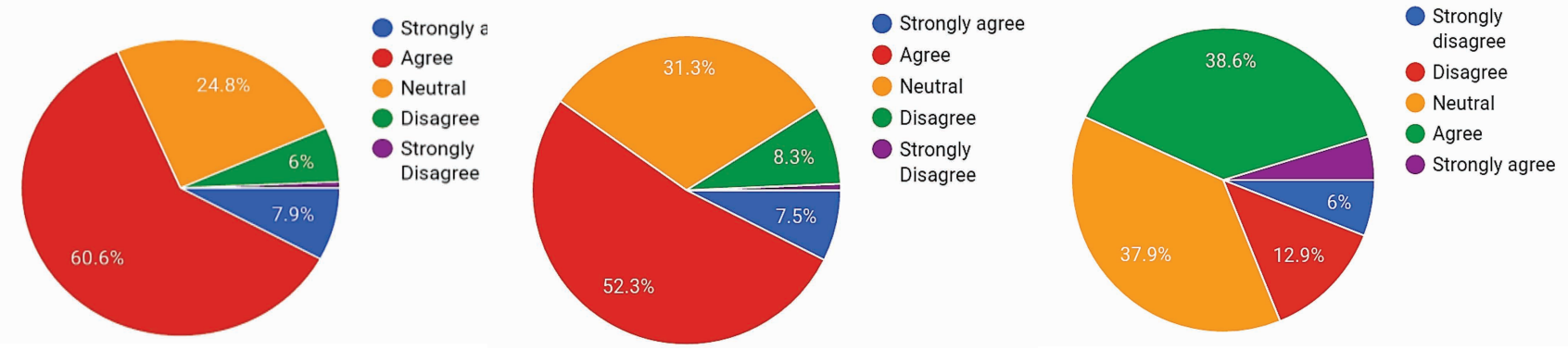
$Q$ 10. Does unhelpful coping strategies such as use of tobacco, alcohol or other drugs reduce pandemic

604 responses
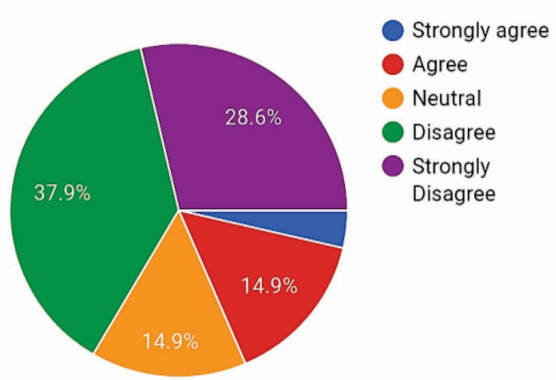

Q 13. Lockdown period can lead to loneliness and depression like feelings 604 responses

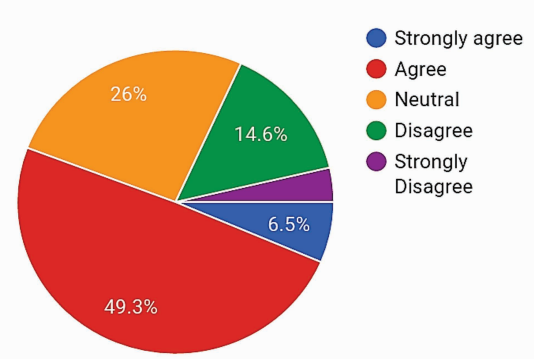

$Q$ 11. Stress and the feelings under pressure associated with work from home during lockdown period 604 responses

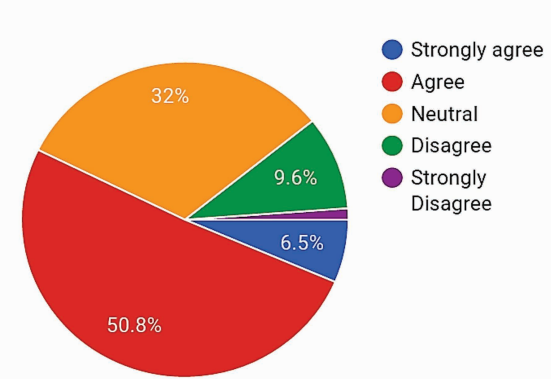

$Q$ 14. During lockdown period whether you are spending less or more time to rest, relax and exercise before and during the outbreak

604 responses

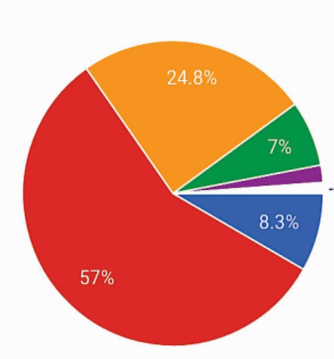

$Q$ 12. Practice prevention measures (e.g. Handwashing, social distancing etc.) creates mental stress

604 responses

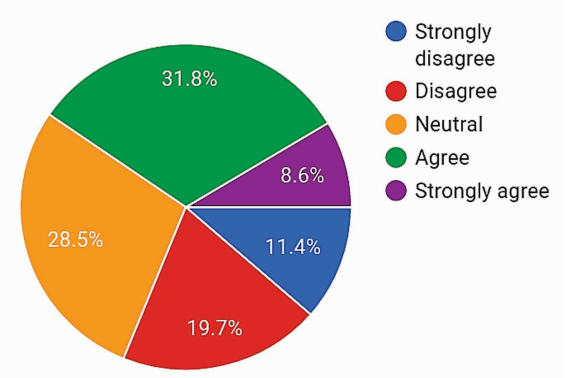

\section{Q 15. Behavior-change modification (follow preventive regulations) can improve your mental stress \\ 604 responses}
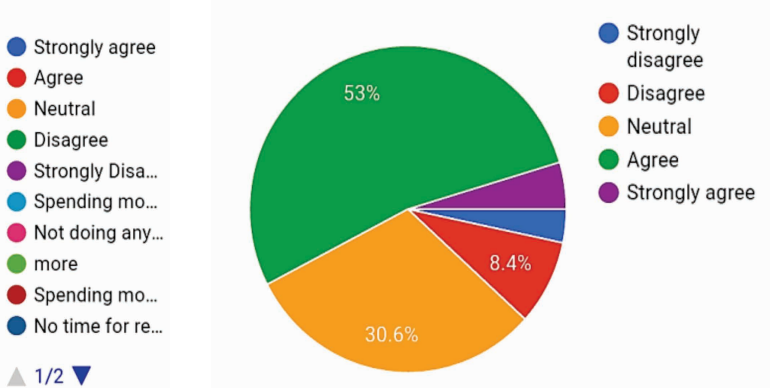

FIGURES 1-15. The responses to the questions from the self-reported questionnaire

and feel stigmatized towards people present with symptoms which might be due to simple flu. Only $15.4 \%$ had gone through any infectious disease in past and had a fear of reliving it. About $60 \%$ were stressed due to social media which spreads rumors and false claims. $43.2 \%$ respondents agreed that they feel anxious and distressed while watching news about COVID-19. Around 60\% samples are facing stress from work, financial stress, and feels helpless during this pandemic and a large number of respondents disagreed on the fact of using coping strategies like alcohol, tobacco or drugs. $75.9 \%$ were in favor of the fact that lockdown period could lead to loneliness and depression like feelings. $40.4 \%$ respondents found to be agreed that preventive measures like washing hands, social distancing creates mental stress. And about 55\% samples agreed on the fact that "Mental stress could be improved by behavior-change modifications".

\section{DISCUSSION}

Since the WHO has declared COVID-19 as a pandemic officially, it started influencing the psychological state of the people across India.

This study collected information about the psychological health in different states of India through a self-reported questionnaire and found that COVID-19 pandemic and lockdown period significantly affect mental health of the population. The finding shows that population's concern about family and health had increased. Study confirmed that people showed more negative emotions 
like depression and anxiety; there were less positive emotions after the declaration of lockdown due to COVID-19 pandemic. Although social risk judgment had increased and satisfaction about life seems to be decreased after announcement of COVID-19. Emotional and social functioning of the population got affected by the lockdown period during COVID-19 and due to increase in load of work at home and other financial problems, people were more prone to stress and anxiety. Moreover, preventive measures and regulation policies like travel restriction and home confinement made the life worse and reduced satisfaction. The main aim of this study was to assess the psychological health of the people in India during lockdown and to explore the factors which influence their psychological state and it is found that about $55.8 \%$ people agreed on the fact that lockdown period leads to negative emotions like sleep disturbances, anxiety and depression which is in agreement with previous research [4]. Li et al. findings suggested that negative impact on mental health [anxiety, depression] and fear to social risks were increased, while the positive behavior and satisfactory feelings decreased [4]. Others researchers also reviewed and considered published articles and previous infection outbreaks and concluded that this COVID-19 outbreak is leading to psychological issues like stress, anxiety, depressive symptoms etc. [3].

A nationwide survey of psychological distress among Chinese people in COVID-19 epidemic measured the prevalence and severity of psychological distress, mental burden on society and concluded that $35 \%$ respondents experience mild to moderate mental distress and $5.14 \%$ respondents experience severe psychological distress [1]. Hence, our study also supported that nearly half of the population experience mental distress due to this pandemic. Another longitudinal study on the psychological health of general population during COVID-19 pandemic in China concluded that respondents - those were experiencing moderate to severe stress, depression, and anxiety were $8.1 \%$ $16.5 \%$ and $28.8 \%$ respectively and after 4 weeks of the epidemic there were no changes in mental health more than $0.05 \%$ because of the protective measures [13].

Brook et al. conducted a study to explore the impact of COVID-19\& lockdown period on psychological health. Depression, stress and anxiety were assessed in 1000 respondents by DASS- 21 . They conclude that stress and anxiety was common in 21-25 age group and depression symptoms was common in 35 years of age and above which supports our study findings that middle age group has correlation with the perceived anxiety [14].

The result of this present study indicate that stress anxiety and depression are seen in more the $50 \%$ of the respondents which is in concomitant with previous research conducted in Italy [2]. Cellini et al. concluded that $242 \%$ of the entire respondents were experiencing moderate to severe depression, $32.6 \%$ samples with moderate to severe symptoms of anxiety, and 50.12\% with moderate to severe symptoms of stress and also $40.5 \%$ $52.4 \%$ respondents were experiencing poor sleep quality. Another Indian cross-sectional study and a semi- structured questionnaire was developed and shared to the convenient samples through emails, whatsapp and other platforms. 662 samples concluded that $29.5 \%$ respondents are aware of the mode of spreading and other risk factors, more than $96 \%$ respondents are in favor of preventive measures like home- quarantine, self- isolation and social distancing, $40 \%$ respondents have phobia of contraction of infection, $72 \%$ respondents are worried about themselves and family members and $75 \%$ of the respondents are agreed on the need of mental health care for the psychologically distressed individuals [15].

It is found that due to exponential growth in the patient numbers cases of death all over the world which leads to extension of lockdown period, has result in increased anxiety due to home isolation, social distancing and fear. However no significant differences were found in gender or region and level of negative emotions.

Consistent with our hypothesis, the lockdown period stressors like lack of social contacts, home-isolation, preventive measures, and stigma to person with symptoms like coughing and sneezing which might be seasonal, has direct effects on the daily life and mental health of the population and is positively associated with anxiety and depression [6].

The study had the limitation that only educated population and the people who use email-IDs and ability to understand English can be represented, hence this study is not generalized to the whole population. The study can be generalized to the un- 
educated people also, so it should be generalized to the whole population.

\section{CONCLUSIONS}

Majority of people has realized the lockdown have significant impact on psychological health status of people. The focus towards the prevention of transmission of corona virus infection may distract attention from psychological consequences of the lockdown period during this pandemic but this

\section{REFERENCES}

1. Qiu J, Shen B, Zhao M, Wang Z, Xie B, Xu Y. A nationwide survey of psychological distress among Chinese people in the COVID-19 epidemic: implications and policy recommendations. Gen Psychiatr. 2020;33(2):e100213.

2. Cellini N, Canale N, Mioni G, Costa S. Changes in sleep pattern, sense of time and digital media use during COVID-19 lockdown in Italy. J Sleep Res. 2020 Aug;29(4):e13074.

3. Torales J, O'Higgins M, Castaldelli-Maia JM, Ventriglio A. The outbreak of COVID-19 coronavirus and its impact on global mental health. International Journal of Social Psychiatry. 2020 Jun;66(4):317-20.

4. Li S, Wang Y, Xue J, Zhao N, Zhu T. The Impact of COVID-19 Epidemic Declaration on Psychological Consequences: A Study on Active Weibo Users. Int J Environ Res Public Health. 2020;17(6):2032.

5. Banerjee D. How COVID-19 is overwhelming our mental health. Nature India. 2020;26:2020.

6. Cao W, Fang Z, Hou G, Han M, Xu X, Dong J, Zheng J. The psychological impact of the COVID-19 epidemic on college students in China. Psychiatry Res. 2020 May 1;287:112934.

7. Mukhtar S. Mental health and emotional impact of COVID-19: applying health belief model for medical staff to general public of Pakistan. Brain Behav Immun. 2020;87:28-29.

8. Fiorillo A, Gorwood P. The consequences of the COVID-19 pandemic on mental health and implications for clinical practice. European Psychiatry. 2020;63(1):e32. may evolve into a serious and long-term mental health problems and personality disorders like obsessive-compulsive disorder, depression etc. Measures should be taken to address consequences of this pandemic among the general population and attention should be given towards the mental health of the population. The news and claims from media and social media should be filtered and controlled. Supportive measures for psychological health should be promoted.

Conflict of interest: none declared Financial support: none declared

9. Ornell F, Schuch JB, Sordi AO, Kessler FH. "Pandemic fear" and COVID-19: mental health burden and strategies. Braz J Psychiatry. 2020 Jun;42(3):232-5.

10. Pfefferbaum B, North CS. Mental Health and the COVID-19 Pandemic. N Engl J Med. 2020 Aug 6;383(6):510-512.

11. Zandifar A, Badrfam R. Iranian mental health during the COVID-19 epidemic. Asian J Psychiatr. 2020;51:101990.

12. Vijayaraghavan $P$, Singhal D. A descriptive study of Indian general public's psychological responses during COVID-19 pandemic lockdown period in India. PsyArXiv.2020 April 13.

13. Wang C, Pan R, Wan X, Tan Y, Xu L, Mclntyre RS, et al. A longitudinal study on the mental health of general population during the COVID-19 epidemic in China. Brain Behav Immun. 2020 Jul 1;87:40-8.

14. Brooks SK, Webster RK, Smith LE, Woodland L, Wessely S, Greenberg N, et al. The psychological impact of quarantine and how to reduce it: rapid review of the evidence. The Lancet. 2020; 395:912-920.

15. Roy D, Tripathy S, Kar SK, Sharma N, Verma SK, Kaushal V. Study of knowledge, attitude, anxiety \& perceived mental healthcare need in Indian population during COVID-19 pandemic. Asian J Psychiatr. 2020 Jun 1;51:102083. 